\title{
Chemical detectors or polarity cues?
}

DOI:

10.1038/nrm2111

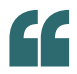

How do cells

translate

the spatial

information

provided by

chemoattractant

gradients into

directed cell

movement?
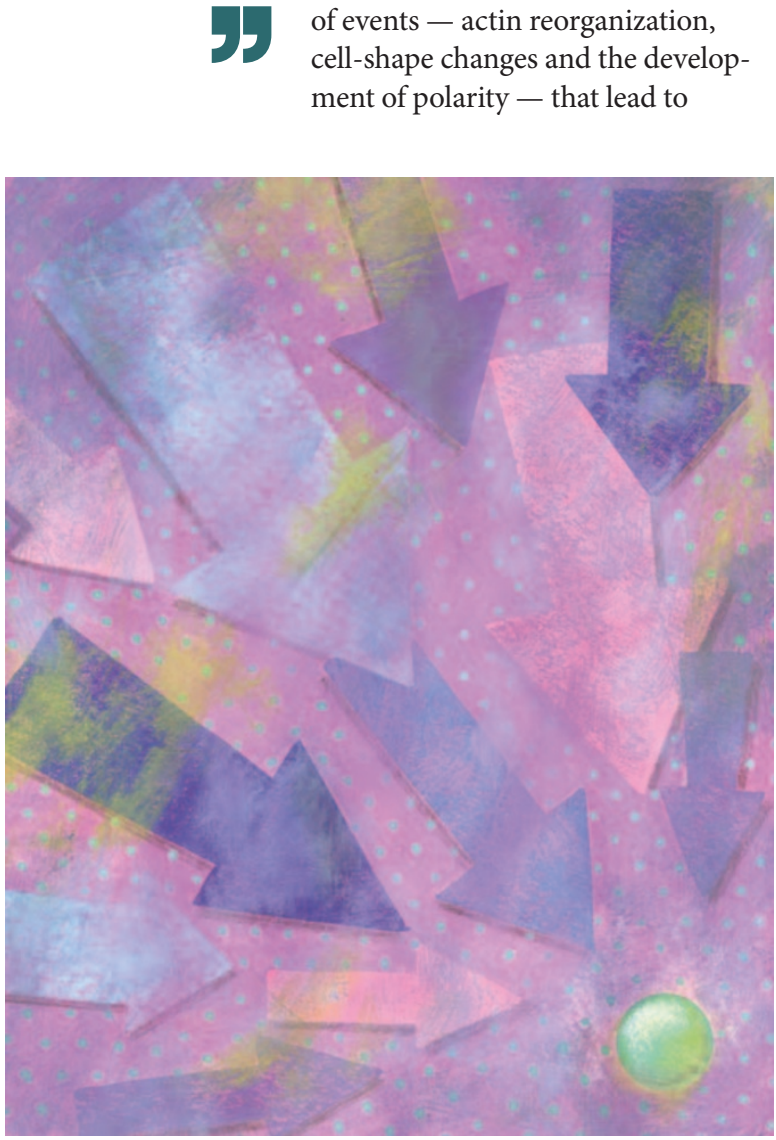

the migration of the cell towards a chemoattractant gradient. Previous studies in Dictyostelium discoideum have shown that phosphatidylinositol 3-kinase (PI3K) proteins are recruited to the plasma membrane at the front of cells, resulting in the localized production of the lipid second messenger PtdIns $(3,4,5) \mathrm{P}_{3}$. By contrast, the phosphatase and tensin homologue (PTEN) is recruited to the back and sides of cells, where it dephosphorylates PtdIns $(3,4,5) \mathrm{P}_{3}$.

Nishio et al. and Ferguson et al. now extend these observations by investigating the dynamic distribution of phosphoinositides in primary neutrophils. Both groups studied neutrophils harvested from transgenic mice that express the pleckstrin homology (PH) domain of AKT/protein kinase $\mathrm{B}(\mathrm{PKB})$ fused to green fluorescent protein (GFP), a bioprobe for PtdIns $(3,4,5) \mathrm{P}_{3}$. Expression of this construct did not interfere with chemotaxis and was strongly localized to the front of the neutrophils. So, how does PI3K activity regulate neutrophil chemotaxis? Ferguson et al. showed that $P I 3 K \gamma^{-/-}$cells had migratory defects on surfaces coated with fibrinogen, but did not observe any chemotaxis defects on uncoated glass. They also found that although the initial phase of chemoattractant-induced polarized actin polymerization was normal in the $P I 3 K \gamma$ knockouts, the proportion of cells that remain polarized over longer time courses was reduced. Using albumin-coated surfaces, Nishio et al. reported that neutrophils from $\mathrm{PI} 3 \mathrm{~K}^{-/-}$mice migrated at about half the speed of wild-type cells. Nishio et al. also found that loss of PTEN did not interfere with neutrophil chemotaxis.
So, if PTEN is not involved in this process, which phosphatase regulates PtdIns $(3,4,5) \mathrm{P}_{3}$ dephosphorylation? Loss of the 5-phosphatase SHIP1 (SH2-domain-containing inositol 5-phosphatase-1) severely impaired neutrophil motility. Ship $1^{-/-}$neutrophils had a flat, unpolarized morphology that was associated with increased levels of PtdIns $(3,4,5) \mathrm{P}_{3}$. In a chemoattractant gradient, Ship $1^{-1-}$ cells did not acquire the characteristic polarized morphology and the speed of migration was reduced rather than increased.

Taken together, these two studies validate the results from model systems, indicating that $\operatorname{PtdIns}(3,4,5) \mathrm{P}_{3}$ influences cell motility. Although these findings highlight the important function of PtdIns $(3,4,5) \mathrm{P}_{3}$, it is also clear that regardless of whether there is a deficiency or an excess of this second messenger, cells still can move towards chemoattractants. Ferguson et al. conclude that $\operatorname{PtdIns}(3,4,5) \mathrm{P}_{3}$ is not a main component of the "neutrophil compass", whereas Nishio et al. propose a model in which PI3K and SHIP1 cooperatively confine $\operatorname{PtdIns}(3,4,5) \mathrm{P}_{3}$ to the prospective leading edge. They speculate that PtdIns $(3,4,5) \mathrm{P}_{3}$ facilitates the formation of the leading lamellar protrusion that is necessary for full polarization and motility, but does not determine its direction.

Ekat Kritikou

ORIGINAL RESEARCH PAPERS Nishio, $\mathrm{M}$. et al.

Control of cell polarity and motility by the

Ptdlns $(3,4,5) \mathrm{P}_{3}$ phosphatase SHIP1. Nature Cell Biol. 9, 36-44 (2007) | Ferguson, G. J. et al. PI(3)K $\gamma$ has an important context-dependent role in neutrophil chemokinesis. Nature Cell Biol. 9 , 86-91 (2007)

FURTHER READING Franca-Koh, J., Kamimura, Y.

$\xi$ Devreotes, P. N. Leading-edge research:

$\operatorname{Ptd} \operatorname{lns}(3,4,5) \mathrm{P}_{3}$ and directed migration.

Nature Cell Biol. 9, 15-17 (2007) 